\title{
Silver Nanoparticles: Green Route, Stability and Effect of Additives
}

\author{
Zaheer Khan $^{1,2 *}$, Javed Ijaz Hussain ${ }^{1}$, Sunil Kumar ${ }^{3}$, Athar Adil Hashmi ${ }^{1}$, Maqsood Ahmad Malik ${ }^{2}$ \\ ${ }^{1}$ Department of Chemistry, Jamia Millia Islamia (Central University), New Delhi, India; ${ }^{2}$ Department of Chemistry, Faculty of Sci- \\ ence, King Abdul Aziz University, Jeddah, Saudi Arabia; ${ }^{3}$ Department of Chemistry, University of Delhi, New Delhi, India. \\ Email: *drkhanchem@yahoo.co.in
}

Received March 27 th $^{\text {, 2011; revised June 29 }}{ }^{\text {th }}$, 2011; accepted July $26^{\text {th }}, 2011$.

\begin{abstract}
Colloidal silver nanoparticles were prepared by reducing silver nitrate with oxalic acid in presence of cetyltrimethylammonium bromide (CTAB). The synthesized silver particles show an intense surface plasmon band in the visible region. The work reported in this paper describes the effect of concentration of various additives ( $\mathrm{NaCl}, \mathrm{NaBr}, \mathrm{NaNO}_{3}, \mathrm{Na}_{2} \mathrm{SO}_{4}$ and $\mathrm{NaH}_{2} \mathrm{PO}_{4}$ ) and ammonia on the growth and stability of Ag-nanoparticles. In all the cases the rate decreases as the [electrolytes] or [ammonia] increases. The nature, polarizability and coordinating ability of the anions play vital roles for nucleus formation and the growth process, which subsequently form different size particles. Transmission electron microscopy, selected areas electron diffraction, and UV-visible spectroscopy have been employed to characterize Ag-nanoparticles. The effect of the following variables on the particle size and size distribution was investigated: the [oxalic acid], [CTAB] and $\left[\mathrm{Ag}^{+}\right]$. The nanoparticles are stable in $\mathrm{NaNO}_{3}$ and $\mathrm{NaH}_{2} \mathrm{PO}_{4}$ solutions; but $\mathrm{NaCl}, \mathrm{NaBr}$ and $\mathrm{Na}_{2} \mathrm{SO}_{4}$ causes their aggregation.
\end{abstract}

Keywords: Silver Nanoparticles, Stability, Oxalic Acid, Additives, Ammonia

\section{Introduction}

The literature is replete with the investigations of the use of noble metal nanoparticles(NP) (silver, gold and platinum) deposited on nanosized $\mathrm{TiO}_{2}$ and/or $\mathrm{WO}_{3}$ for carrying out the photocatalytic destruction of oxalic acid in aqueous solution [1-4]; but the preparation and characterization of Ag-NP involving oxalic acid (sacrificial electron donors) has been neglected. Oxalic acid, an important reductant in many organic and bioorganic redox reactions and its reduction process is eco-friendly and has gained importance in green chemistry. It is found naturally in varying concentrations, occurring in many plants such as tea, rhubarb, spinach, cocoa, nuts, berries and beans. Organic oxalic acid is essential for human body and is completely harmless if consumed in organic form. Inorganic oxalic acid causes trouble to human body. When ingested, oxalic acid removes calcium from the blood. Kidney damage can be expected as the calcium is removed from the blood in the form of calcium oxalate. Within the sub-group of 'weak acids', it is relatively strong $\left(\mathrm{pK}_{1}=1.22 ; \mathrm{pK}_{2}=4.28 ; \mathrm{E}_{0}=+0.49 \mathrm{~V}\right.$ for $\mathrm{C}_{2} \mathrm{O}_{4} \mathrm{H}_{2} / \mathrm{CO}_{2}$ system in acid solution).

Advanced Ag-NP have been synthesized by thermal decomposition and microwave irradiation methods by the decomposition of silver oxalate in a glycol medium using polyvinyl alcohol and polyvinyl pyrolidone as the capping agents, respectively [5,6]. Itoh, et al prepared silver nanoparticles via thermal decomposition of oxalate-bridging silver oleylamine complexes at $150^{\circ} \mathrm{C}$ [7]. Even though many methods have been reported in the literature, the interest in the field of genesis of Ag-NP has not diminished. Among the various methods available, chemical reduction of metal salts is one of the possible ways of producing Ag-nanostructures as stable, colloidal dispersions in water or organic solvents [8]. The chemical reduction methods are probably the most versatile, economical and easy to control the shape and size of metal-NP. For stabilization of small particles, the use of polymers, phospholipids, triblock polymers, ligands, solid matrix and surfactants has also been suggested [9-14]. Although a number of stabilizers are available for the stabilization of nanosize particles in solution, these are associated with some demerits [15]. The preparation of these materials in green solvents, such as water [16] and other non-toxic solvents is becoming popular. In this content, surfactant aggregates, especially micelles, reverse micelles and macro emulsions, will get 
an edge over other stabilizers [17-20].

Henglein prepared the colloidal silver particles by radiation method using 2-propanol, $\mathrm{AgClO}_{4}$ and polyphosphate as reductant, oxidant and stabilizer, respectively, discussed the effects of adsorbed additives, organic solvent, and some metal cations (KI, NaSH, $\mathrm{C}_{6} \mathrm{H}_{5} \mathrm{SH}, \mathrm{H}_{2} \mathrm{~S}, \mathrm{O}_{2}, \mathrm{CCl}_{4}, \mathrm{Na}^{+}, \mathrm{Ag}^{+}, \mathrm{Ba}^{2+}, \mathrm{Cd}^{2+}, \mathrm{Ni}^{2+}, \mathrm{Hg}^{2+}$ ) on the stability of resulting silver particles, and suggested that $\mathrm{Ag}_{4}{ }^{2+}$ species can be stabilized for along time in presence of a polyanion even under air and growth stops at the stage of this species [21-25]. Chemisorbed metal cations effect was interpreted in terms of the donation of electron density from the silver particles to the adsorbed cations. Henglein also monitored the stepwise growth of first silver clusters $\mathrm{Ag}^{+}$ion reduction in aqueous solution by spectroscopic methods [26]. Considerable spectroscopic data have accumulated on the synthesis of various Ag-NP by silver-mirror reaction. It has been established that ammonia concentrations and nature of reducing agents play an important role in controlling the morphologies of NP [27,28]. However, details of silver(I) reduction (Ag-NP formation) involving oxalic acid as reductant are not yet well-known in the absence and presence of additives or ammonia. We have chosen oxalic acid to see the effects of different additives, because its oxidation product, i.e., $\mathrm{CO}_{2}$, has no complex-formining tendency. A study of such a redox reaction should provide information relevant to the hypothesis previously advanced to the silver-mirror reaction $[29,30]$. We have carried out the present study with the following aims: (1) to determine the effects of different variables on the rates of Ag-NP; (2) to establish the role of different additives and ammonia on the growth of Ag-NP; and (3) to determine the effects of inorganic salts on the stability of silver sol. The observed results and the probable explanations detailed in this paper.

\section{Experimental Section}

\subsection{Chemicals}

Oxalic acid $\left(\mathrm{C}_{2} \mathrm{H}_{2} \mathrm{O}_{4} \cdot 2 \mathrm{H}_{2} \mathrm{O}\right.$, reductant, $\left.99 \%\right)$, silver nitrate $\left(\mathrm{AgNO}_{3}\right.$, oxidant, $\left.99 \%\right)$, ammonia, cetyltrimethylammonium bromide (CTAB), ammonia, and inorganic electrolytes $\left(\mathrm{NaCl}, \mathrm{NaBr}, \mathrm{NaNO}_{3}, \mathrm{Na}_{2} \mathrm{SO}_{4}\right.$ and $\left.\mathrm{NaH}_{2} \mathrm{PO}_{4}\right)$ were obtained from Merck India and used with out further purification. Deionized water was used to prepare all of the aqueous solutions. $\mathrm{AgNO}_{3}$ solutions were stored in a dark glass bottle.

\subsection{Preparation and Characterization of Ag-NP}

CTAB solution $\left(0.01 \mathrm{~mol} \cdot \mathrm{dm}^{-3}, 4.0 \mathrm{ml}\right)$ was mixed with $0.01 \mathrm{~mol} \cdot \mathrm{dm}^{-3} \mathrm{AgNO}_{3}(10.0 \mathrm{ml})$. A $0.01 \mathrm{~mol} \cdot \mathrm{dm}^{-3}$ oxalic acid $(2.0 \mathrm{ml})$ was added to this solution. The color of the reaction mixture gradually changed from colorless to prefect transparent yellow, indicating the formation of Ag-NP [5]. UV-260 Shimadzu, with $1 \mathrm{~cm}$ quartz cuvettes spectrophotometer was used to monitor the optical transmission spectra of the silver sol under different experimental conditions. The prepared NP was analyzed by transmission electron microscopy (TEM) on a transmission electron microscope (JEOL, JEM-1011; Japan). Samples were prepared by placing a drop of working solution on a carbon-coated standard copper grid (300 mesh) operating at $80 \mathrm{kV}$. An Accumet, fisher scientific digital $\mathrm{pH}$ meter 910 fitted with a combination electrode was used for $\mathrm{pH}$ measurements.

\subsection{Determination of Critical Micelle Concentration (CMC)}

The cmc values were determined from plots of the specific conductivity versus $[\mathrm{CTAB}]$ in the absence and presence of $\mathrm{AgNO}_{3}$ and oxalic acid. The break point of nearly two straight-line portions in the plot are taken as an indication of micelle formation and this corresponds to the cmc of CTAB [31] and found to be $10.1 \times 10^{-4}$, $8.7 \times 10^{-4}, 8.8 \times 10^{-4}, 8.8 \times 10^{-4}$ and $8.9 \times 10^{-4} \mathrm{~mol} \cdot \mathrm{dm}^{-3}$ for water + CTAB, CTAB + oxalic acid $\left(2.0 \times 10^{-4}\right.$ $\left.\mathrm{mol} \cdot \mathrm{dm}^{-3}\right), \mathrm{CTAB}+\mathrm{AgNO}_{3}\left(2.0 \times 10^{-4} \mathrm{~mol} \cdot \mathrm{dm}^{-3}\right)$, $\mathrm{CTAB}+$ oxalic acid $+\mathrm{AgNO}_{3}$, respectively, at $30^{\circ} \mathrm{C}$.

\section{Results and Discussion}

\subsection{Optimization of Reaction Conditions for Transparent Ag-Sol}

Generally, aqueous solutions of oxalic acid and $\mathrm{AgNO}_{3}$ were used to the preparation of silver oxalate (white precipitate) [5-7]. Therefore, choice of the best conditions for the preparation of Ag-NP is a crucial problem that we address first. Under our experimental conditions used ([oxalic acid (from $4.0 \times 10^{-4} \mathrm{~mol} \cdot \mathrm{dm}^{-3}$ to 14.0 $\times 10^{-4} \mathrm{~mol} \cdot \mathrm{dm}^{-3}$ ), $\left[\mathrm{Ag}^{+}\right]$(from $4.0 \times 10^{-4} \mathrm{~mol} \cdot \mathrm{dm}^{-3}$ to $20.0 \times 10^{-4} \mathrm{~mol} \cdot \mathrm{dm}^{-3}$, [CTAB] (from $2.0 \times 10^{-4} \mathrm{~mol} \cdot \mathrm{dm}^{-3}$ to $14.0 \times 10^{-4} \mathrm{~mol} \cdot \mathrm{dm}^{-3}$ at $30^{\circ} \mathrm{C}$ ), we did not observe the appearance of white precipitate, ruled out the possibility of silver oxalate as the reaction product. It is well known that colloidal aqueous solution of metal particles undergoes acid hydrolysis or is unstable in acidic medium, stability of metal nanoparticles depends strongly on the $\mathrm{pH}$ of the working reaction mixture and its growth can be stopped by adding the small amounts of minerals acids $[23,32,33]$. Control of $\mathrm{pH}$ is not as straightforward in micellar solutions as in ordinary solvents $[34,35]$. However, a series of experiments were performed in order to see any change in the $\mathrm{pH}$ of the working solution. The $\mathrm{pH}$ values were found to be nearly constant with increasing [oxalic acid] (Table 1). It is not surprising from 
Table 1. Values of $\mathrm{k}_{\mathrm{obs}}$ as a function of [oxalic acid], [CTAB] and [Ag+] for the Ag-NP formation at $30^{\circ} \mathrm{C}$.

\begin{tabular}{|c|c|c|c|c|}
\hline $10^{4}$ [oxalic acid] $\left(\mathrm{mol} \cdot \mathrm{dm}^{-3}\right)$ & $10^{4}[\mathrm{CTAB}]\left(\mathrm{mol} \cdot \mathrm{dm}^{-3}\right)$ & $10^{4}\left[\mathrm{Ag}^{+}\right]\left(\mathrm{mol} \cdot \mathrm{dm}^{-3}\right)$ & $\mathrm{pH}$ & $10^{4} \mathrm{k}_{\mathrm{obs}}\left(\mathrm{s}^{-1}\right)$ \\
\hline 0.0 & 8.0 & 2.0 & 3.2 & 0.0 \\
\hline 4.0 & & & 3.2 & 7.2 \\
\hline 6.0 & & & 3.4 & 7.2 \\
\hline 8.0 & & & 3.3 & 7.1 \\
\hline 10.0 & & & 3.3 & 7.0 \\
\hline 12.0 & & & 3.2 & 7.4 \\
\hline 14.0 & & & 3.3 & 7.3 \\
\hline 20.0 & & & 3.2 & 7.3 \\
\hline \multirow[t]{9}{*}{4.0} & 2.0 & 20 & 3.3 & 3.1 \\
\hline & 4.0 & & 3.2 & 4.6 \\
\hline & 6.0 & & 3.1 & 5.8 \\
\hline & 8.0 & & 3.2 & 7.2 \\
\hline & 10.0 & & 3.1 & 6.2 \\
\hline & 12.0 & & 3.0 & 4.8 \\
\hline & 14.0 & & 3.3 & 3.6 \\
\hline & 16.0 & & 3.2 & yellowish turbidity \\
\hline & 20.0 & & 3.1 & yellowish turbidity \\
\hline \multirow[t]{7}{*}{4.0} & 8.0 & 4.0 & 3.1 & no yellow color \\
\hline & & 8.0 & 3.3 & 4.1 \\
\hline & & 10.0 & 3.3 & 5.4 \\
\hline & & 12.0 & 3.1 & 6.6 \\
\hline & & 14.0 & 3.2 & 6.6 \\
\hline & & 16.0 & 3.1 & 6.8 \\
\hline & & 20.0 & 3.2 & 7.2 \\
\hline
\end{tabular}

the fact that oxalic acid is a weak acid. Spectra of silver sol solution possess a surface resonance plasmon (SPR) band in the vicinity of 375 to $450 \mathrm{~nm}$ [36]. When $\mathrm{AgNO}_{3}$ $\left(20.0 \times 10^{-4} \mathrm{~mol} \cdot \mathrm{dm}^{-3}\right)$ and CTAB $\left(10.0 \times 10^{-4} \mathrm{~mol} \cdot \mathrm{dm}^{-3}\right)$ reaction solution was allowed to react with oxalic acid $\left(4.0 \times 10^{-4} \mathrm{~mol} \cdot \mathrm{dm}^{-3}\right)$ in the absence and/or presence of ammonia (from 0.0 to $60.0 \times 10^{-4} \mathrm{~mol} \cdot \mathrm{dm}^{-3}$ ), the colorless reaction solution became transparent yellow. UVvisible spectral studies (Figure 1) showed that the $\mathrm{AgNO}_{3}$-oxalic acid redox reaction resulted in SRP band at $425 \mathrm{~nm}$ which was assigned to the Ag-NP [36]. It should be emphasized here that before examining the effect of electrolytes and ammonia on the stability and growth of Ag-NP, the reaction was studied without adding any agents too.

\subsection{Effect of Reactant Concentrations and Mechanism}

Reduction of $\mathrm{Ag}^{+}$ions by oxalic acid has been studied kinetically as a function of [oxalic acid], $\left[\mathrm{AgNO}_{3}\right]$ and
[CTAB]. The apparent first-order rate constant $\left(\mathrm{k}_{\mathrm{obs}}, \mathrm{s}^{-1}\right)$ were determined from the slopes of $\ln [\mathrm{a} /(1-\mathrm{a})$ versus time plots [37,38]. The rate constant remained unchanged with increase in [oxalic acid] (Table 1), showing first-order dependence with respect to [oxalic acid]. Interestingly, as the $[\mathrm{CTAB}]$ increased from $2.0 \times 10^{-4} \mathrm{~mol} \cdot \mathrm{dm}^{-3}$ to 14.0 $\times 10^{-4} \mathrm{~mol} \cdot \mathrm{dm}^{-3}, \mathrm{k}_{\text {obs }}$ increases, until it reaches a maximum, and then decreases monotonically due to the dilution effect. Kinetic determinations at higher [CTAB] $(\geq$ $16.0 \times 10^{-4} \mathrm{~mol} \cdot \mathrm{dm}^{-3}$ ) were hampered due to the formation of yellowish turbidity (Table 1). We did not observed the formation of yellow color at $\left[\mathrm{AgNO}_{3}\right]=2.0 \times$ $10^{-4} \mathrm{~mol} \cdot \mathrm{dm}^{-3}$. From these data, the over all mechanism for the reaction can be represented in Scheme 1.

\subsection{Salt Effect Results}

Inert salts, especially the inorganic ones, act as catalysts or inhibitors in the micelle mediated reactions [39,40]. Therefore, to see the effects of $\mathrm{NaCl}, \mathrm{NaBr}, \mathrm{NaNO}_{3}$, $\mathrm{Na}_{2} \mathrm{SO}_{4}$ and $\mathrm{NaH}_{2} \mathrm{PO}_{4}$ on the rate of Ag-NP, different 


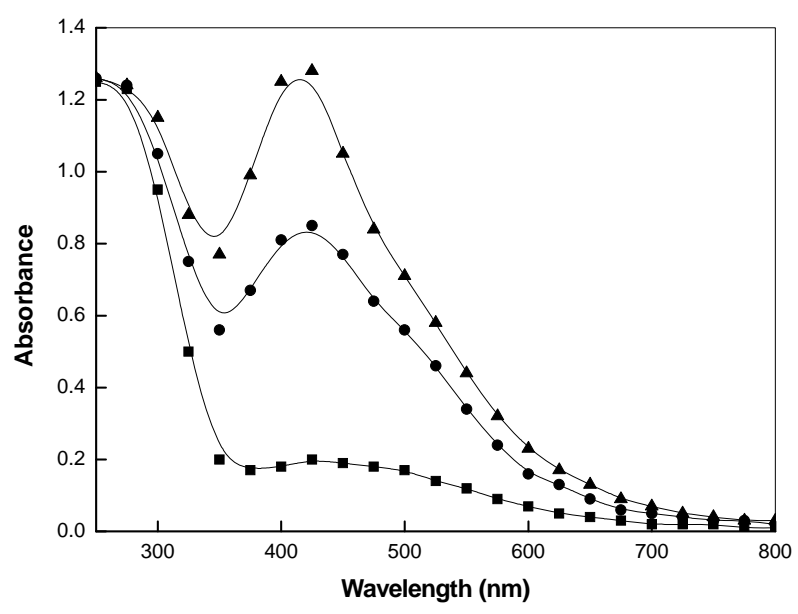

Figure 1. UV-visible spectra of Ag-NP for [oxalic acid] $=4.0$ $\times 10^{-4} \mathrm{~mol} \cdot \mathrm{dm}^{-3},\left[\mathrm{Ag}^{+}\right]=20.0 \times 10^{-4} \mathrm{~mol} \cdot \mathrm{dm}^{-3}$ and $\mathrm{CTAB}=$ $10.0 \times 10^{-4} \mathrm{~mol} \cdot \mathrm{dm}^{-3}$ as a function of time $20(\bullet), 40(\bullet)$ and $60 \mathrm{~min}(\Delta)$ at $30^{\circ} \mathrm{C}$.

$$
\begin{aligned}
& \left.\right|_{\mathrm{COOH}} ^{\mathrm{COOH}}+\mathrm{Ag}^{+} \longrightarrow \mathrm{Ag}^{0}+\mathrm{CO}_{2}+\underset{\begin{array}{c}
\mathrm{COOH} \\
\text { (radical) }
\end{array}}{\stackrel{\bullet}{\mathrm{CO}}} \\
& \stackrel{\bullet}{\mathrm{COOH}}+\mathrm{Ag}^{+} \stackrel{\text { fast }}{\longrightarrow} \mathrm{CO}_{2}+\mathrm{Ag}^{0}+\mathrm{H}^{+} \\
& \mathrm{Ag}^{0}+\mathrm{Ag}^{+} \stackrel{\text { fast }}{\longrightarrow} \mathrm{Ag}_{2}^{+} \\
& \mathrm{Ag}_{2}^{+}+\mathrm{Ag}_{2}^{+} \stackrel{\text { fast }}{\longrightarrow} \mathrm{Ag}_{4}^{2+}
\end{aligned}
$$

Scheme 1. Reduction of $\mathrm{Ag}^{+}$by oxalic acid.

amounts of these salts were added to the reaction mixture at $8.0 \times 10^{-4} \mathrm{~mol} \cdot \mathrm{dm}^{-3} \mathrm{CTAB}$. Reaction solution became turbid in presence of $\mathrm{NaCl}$ or $\mathrm{NaBr}\left(\geq 2.0 \times 10^{-2} \mathrm{~mol} \cdot \mathrm{dm}^{-3}\right)$, which increases with these salts due to the strong $\mathrm{Cl}^{-}$or $\mathrm{Br}^{-}$ions affinity for $\mathrm{Ag}^{+}$ions. The curves are explained by taking into account two effects of anions, First, exclusion of reactants from the reaction site (i.e., Stern layer, as most of the ionic micelle mediated reactions are believed to occur in this region). As we increase the [electrolytes], the $\mathrm{NO}_{3}^{-}, \mathrm{SO}_{4}^{2-}$ and $\mathrm{H}_{2} \mathrm{PO}_{4}^{-}$will try to get incorporated into the reaction site through electrostatic interactions, which are the normal behaviors found in the literature [39-41]. Second, Fermi level of particles increases with a rise in the concentrations of nucleoplilies ( $\mathrm{NO}_{3}^{-}, \mathrm{SO}_{4}^{2-}$ and $\mathrm{H}_{2} \mathrm{PO}_{4}^{-}$) due to the adsorption of these anions on to the surface of Ag-NP [23]. Hence, the $\mathrm{k}_{\mathrm{obs}}$ decrease as the [electrolytes] increases. The difference in the action of $\mathrm{NO}_{3}^{-}, \mathrm{SO}_{4}^{2-}$ and $\mathrm{H}_{2} \mathrm{PO}_{4}^{-}$ion is due to the fact that $\mathrm{H}_{2} \mathrm{PO}_{4}^{-}$is specifically, i.e., high polarizability, incorporated into the reaction site [42].

The adsorption of additives on colloidal silver parti- cles in aqueous solution is accompanied by strong optical changes. The SRP absorption band is damped and its maximum is shifted to shorter or longer wavelengths, depending on the nature of the adsorbed species and its concentrations [21-25, 43, 44]. Stability of the Ag-NP in presence of these salts was also investigated (Figure 2). The SRP band remains unaffected in presence of $\mathrm{NaNO}_{3}$ or $\mathrm{NaH}_{2} \mathrm{PO}_{4}$ (from $25.0 \times 10^{-3}$ to $75.0 \times 10^{-3} \mathrm{~mol} \cdot \mathrm{dm}^{-3}$ ). The intensity of SRP decreased sharply and the spectrum became broader at low concentrations of $\mathrm{Na}_{2} \mathrm{SO}_{4}$. The peak intensity was enhanced (hyperchromic-shift) by in- creasing the $\left[\mathrm{Na}_{2} \mathrm{SO}_{4}\right]$ from $25.0 \times 10^{-3}$ to $75.0 \times 10^{-3} \mathrm{~mol} \cdot \mathrm{dm}^{-3}$. When mono-valent anions (e.g., $\mathrm{NO}_{3}^{-}$or $\mathrm{H}_{2} \mathrm{PO}_{4}^{-}$) are added into the Ag-NP solution, they adsorb onto the surface of silver cluster, $\mathrm{Ag}_{4}^{2+}$, without affecting the nanoparticle dispersivity and no change is observed in SRP band. The bivalent anions such as $\mathrm{SO}_{4}^{2-}$, causes the interaction of one anion with several Ag-NP at low concentrations, such type of multi-interaction causes the aggregation of free Ag-NP, which in turn, decreases the intensity of SRP band. When the anion concentration is increased, enough anions adsorb onto the surface of Ag-NP and a charge reversal of the shell occurs. As a result, redispersal of the Ag-NP occurs. Consequently, intensity of SRP band increases. Interestingly, no turbid solution of $\mathrm{AgCl}$ or $\mathrm{AgBr}$ was detected in presence of $\mathrm{NaCl}$ or $\mathrm{NaBr}$. This result indicated that essentially all $\mathrm{Ag}^{+}$ions were transformed to the $\mathrm{Ag}^{0}$ during the redox process and/or adsorbed on the surface of silver cluster, i.e., $\mathrm{Ag}_{4}^{2+}$. Thus, we may safely conclude that $\mathrm{Cl}^{-}$or $\mathrm{Br}^{-}$ ions could not detach the adsorbed $\mathrm{Ag}^{+}$from the $\mathrm{Ag}_{4}^{2+}$ [37]. In case of $\mathrm{NaCl}$, hyperchromic- and blue-shift of the intensity and SRP band were observed with increasing the $[\mathrm{NaCl}]$, respectively. Immediately after addition of $\mathrm{NaCl}$ the stronger SRP band centered at ca. $425 \mathrm{~nm}$ changed into a broad absorption shoulder at about 400 $\mathrm{nm}$. On the other hand, different behavior was observed for $\mathrm{NaBr}$. No absorption at $425 \mathrm{~nm}$ of colloidal silver appeared. It thus seems that the Ag-NP is rather unstable in presence of $\mathrm{NaBr}$ under the same $[\mathrm{NaCl}]$ and is rapidly converted into larger particles. This red-shift is attributed to the strong interactions between the adsorbed $\mathrm{Ag}^{+}$and $\mathrm{Br}^{-}$ions on the surface of $\mathrm{Ag}_{4}^{2+}$, the nucleoplilicity of the $\mathrm{Br}^{-}$ion is better than that of $\mathrm{Cl}^{-}$ion $[45,46]$. The surface neutralization or adsorption slightly induces the particle aggregation, as reflected by the shift of SPB. It should be emphasized that the solutions were non-opalescent before as well after the addition of $\mathrm{Br}^{-}$as viewed by the naked eye.

\subsection{Ammonia Effect Results}

Ammonia is a mandatory reagent for silver-mirror reac- 

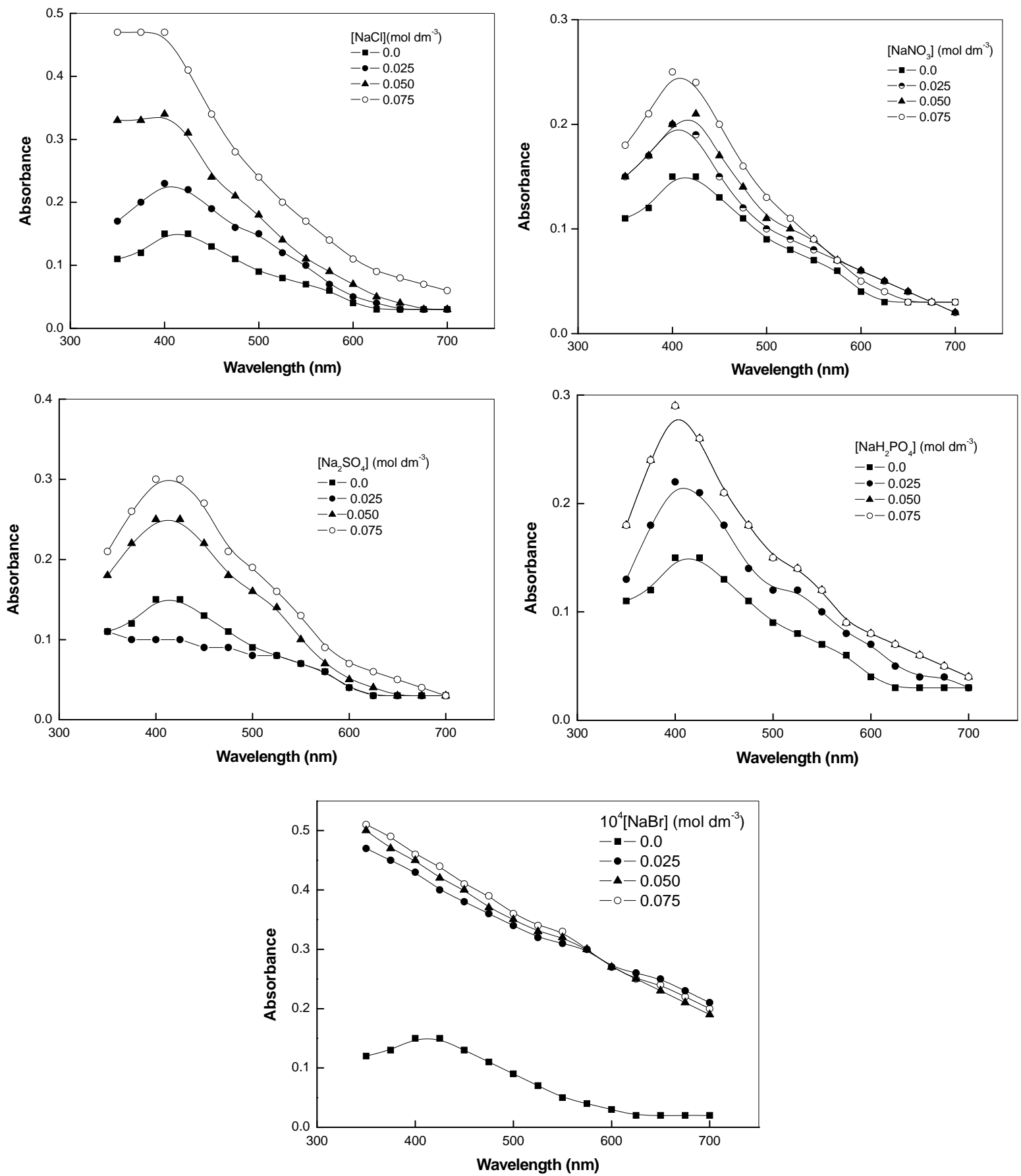

Figure 2. Effect of [electrolytes] on the surface plasma resonance band of Ag-NP. The concentration of Ag-NP was diluted from the original solution by 4 times.

tion and their concentration play a major role in controlling the Ag-NP size and shape [27,47-49]. In order to gain insight into the role of ammonia, the oxalic acidsilver(I) reaction was also studied in presence of [ammonia]. The evolution of the absorption spectra with time is presented in Figure 3 in an ammonia solution containing $4.0 \times 10^{-4} \mathrm{~mol} \cdot \mathrm{dm}^{-3}$ oxalic acid, $20.0 \times 10^{-4} \mathrm{~mol} \cdot \mathrm{dm}^{-3}$
$\mathrm{AgNO}_{3}$ and $10.0 \times 10^{-4} \mathrm{~mol} \cdot \mathrm{dm}^{-3} \mathrm{CTAB}$. As shown in Figure 1 the SRP band centered at about $425 \mathrm{~nm}$ decreased in intensity and shifted to shorter wavelengths with increasing time (blue shift of about $15 \mathrm{~nm}$ ). It seemed possible that the decrease in the intensity was related to the complexation of ammonia with $\mathrm{Ag}^{+}$ions during the course of reaction. To conform this hypothesis, 


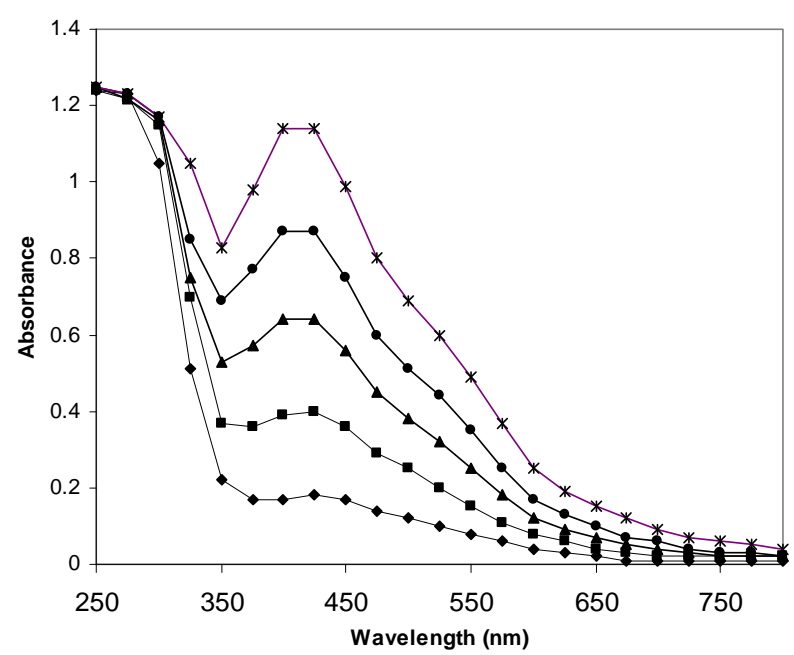

Figure 3. UV-visible spectra of Ag-NP for [oxalic acid] $=4.0$ $\times 10^{-4} \mathrm{~mol} \cdot \mathrm{dm}^{-3},\left[\mathrm{Ag}^{+}\right]=20.0 \times 10^{-4} \mathrm{~mol} \cdot \mathrm{dm}^{-3}$ and $\mathrm{CTAB}=$ $10.0 \times 10^{-4} \mathrm{~mol} \cdot \mathrm{dm}^{-3}$ in presence of $\left[\right.$ ammonia] $=20.0 \times 10^{-4}$ $\mathrm{mol} \cdot \mathrm{dm}^{-3}$ as a function of time $20(\diamond), 40(\square), 60(\Delta), 80(\bullet)$ and $100 \mathrm{~min}(*)$ at $30^{\circ} \mathrm{C}$.

the experiments were performed under different conditions: (i) addition of oxalic acid followed by ammonia and vice versa and (ii) allowing ammonia and $\mathrm{Ag}^{+}$ions reaction to proceed for $10 \mathrm{~min}$, followed by addition of $4.0 \times 10^{-4} \mathrm{~mol} \cdot \mathrm{dm}^{-3}$ oxalic acid. Observations of these experiments are summarized in Figure 4, as absorbanceand $\mathrm{k}_{\mathrm{obs}}$-[ammonia] profiles. At $425 \mathrm{~nm}$, the absorbance first decreased then increased continuously and decreased with [ammonia], respectively, for the certain reaction time i.e., 60 and $20 \mathrm{~min}$, to the experimental condition (i) (Figure 4, $\circ$ and $\bullet$ ) whereas the absorbance first decreased until it reached a maximum then decreased with [ammonia] to the addition of ammonia followed oxalic acid (Figure 4, $\Delta$ ). For the reaction conditions (ii), absorbance decreased progressively with [ammonia] (Figure 4, $\mathbf{)}$ ). The reduction of $\mathrm{Ag}^{+}$ions by oxalic acid results in a fast formation of Ag-NP. Spectroscopic and kinetic results (Figures 1, 3, 4) show that in the presence of ammonia the reduction rate is slower and that significant changes in the reactivity of $\mathrm{Ag}^{+}$ions occur in solutions containing ammonia. It is clear that ammonia play a crucial role in the reduction of $\mathrm{Ag}^{+}$ions by oxalic acid. In the presence of ammonia the $\mathrm{Ag}^{+}$ions are expected to form $\left[\mathrm{Ag}\left(\mathrm{NH}_{3}\right)_{2}\right]^{+}$[50]. The intensity and rate of the Ag-NP decreased after the addition of ammonia, indicating that the formation of $\left[\mathrm{Ag}\left(\mathrm{NH}_{3}\right)_{2}\right]^{+}$species, which ultimately decreases the reduction potential of $\mathrm{Ag}^{+}$ ions as well as the generation of metallic silver at the early stages of the reaction (separates the $\mathrm{Ag}^{+}$ions from the oxalic acid). Instant and/or after $10 \mathrm{~min}$ addition of oxalic acid into the reaction solution $\left(\mathrm{AgNO}_{3}\right.$ and ammonia) also decreases the intensity and rate of Ag-NP

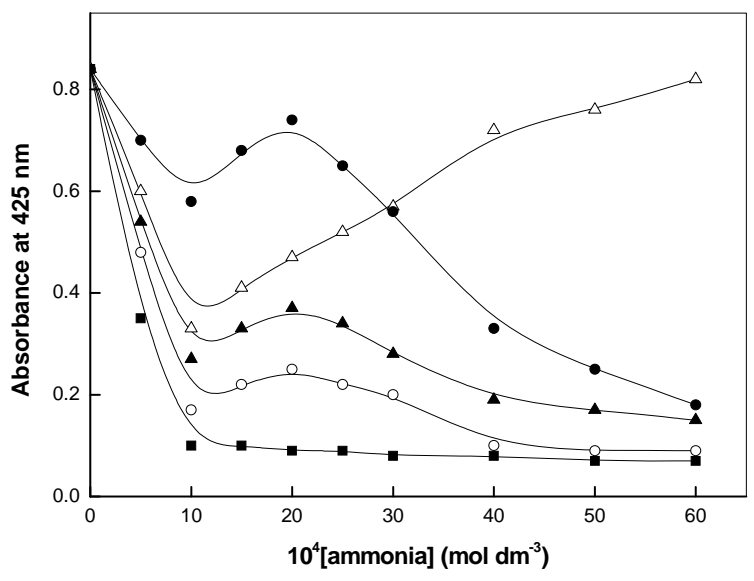

Figure 4. Effect of [ammonia] on the surface plasmon resonance absorbance. Reaction conditions: $[0 x a$ lic acid] $=4.0 \times$ $10^{-4} \mathrm{~mol} \cdot \mathrm{dm}^{-3},\left[\mathrm{Ag}^{+}\right]=\mathbf{2 0 . 0} \times 10^{-4} \mathrm{~mol} \cdot \mathrm{dm}^{-3}$ and CTAB $=8.0$ $\times 10^{-4} \mathrm{~mol} \cdot \mathrm{dm}^{-3}$ under different order of ammonia mixing: (1) $\mathrm{Ag}^{+}, \mathrm{CTAB}$, oxalic acid and ammonia (time $=20(\Delta)$ and $60 \mathrm{~min}(\bullet),(2) \mathrm{Ag}^{+}, \mathrm{CTAB}$, ammonia and oxalic acid (time $=20(\circ)$ and $60 \mathrm{~min}(\Delta)$ and $(3) \mathrm{Ag}^{+}, \mathrm{CTAB}$, ammonia and oxalic acid after $10 \mathrm{~min}(\boldsymbol{\sigma})$.

formation $(\bullet$ and $\boldsymbol{\Delta})$. At higher [ammonia] $\geq 30.0 \times 10^{-4}$ $\mathrm{mol} \cdot \mathrm{dm}^{-3}$, there is no significant changes in the reaction rate. On the basis of these observations, we may safely concluded that oxalic acid is capable to reduce $\mathrm{Ag}^{+}$to $\mathrm{Ag}^{0}$. In presence of ammonia there is a competition between oxalic acid and ammonia to react with $\mathrm{Ag}^{+}$. Obviously, ammonia has strong affinity towards $\mathrm{Ag}^{+}$and small time is enough to form $\left[\mathrm{Ag}\left(\mathrm{NH}_{3}\right)_{2}\right]^{+}$. Complexation lowers the reduction potentials to such an extent that the reactive site (electrons gaining tendency) of $\mathrm{Ag}^{+}$is partially blocked by the presence ammonia molecules in $\left[\mathrm{Ag}\left(\mathrm{NH}_{3}\right)_{2}\right]^{+}$[50] but not totally prevent the $\mathrm{Ag}^{+}$reduction. These results are also in agreement with the idea that once a metal atom which acts as a nucleation center is formed; it acts as a catalyst for the reduction of remaining metal ions present in solution via autocatalysis [51].

In presence of ammonia, Scheme 1 mechanism can be modified as Scheme 2.

The direct oxidation of oxalic acid by $\left[\mathrm{Ag}\left(\mathrm{NH}_{3}\right)_{2}\right]^{+}$is not possible. Thus, the reaction may generally be expressed by Equation (6) $\left(\mathrm{K}_{\mathrm{os}}\right.$ is the rapid equilibrium for the encounter complex formation between the redox couple [52]). By analogy with previous results [52], we assume that complex decomposes in a rate-determining one-step one-electron oxidation-reduction mechanism to give $\mathrm{Ag}^{0}$ and corresponding radical due to the sacrificial electron donor's property of oxalic acid.

\subsection{TEM Images}

Figures 5 and 6 show TEM images of silver sol (or ange- 


$$
\begin{aligned}
& \mathrm{Ag}^{+}+2 \mathrm{NH}_{3} \stackrel{\mathrm{K}_{\mathrm{b}}}{\rightleftharpoons}\left[\mathrm{Ag}\left(\mathrm{NH}_{3}\right)_{2}\right]^{+} \\
& \text {oxalic acid }+\left[\mathrm{Ag}\left(\mathrm{NH}_{3}\right)_{2}\right]^{+} \stackrel{\mathrm{K}_{\mathrm{os}}}{\rightleftharpoons} \underset{\text { (complex) }}{\text { oxalic acid- }\left[\mathrm{Ag}\left(\mathrm{NH}_{3}\right)_{2}\right]^{+}}
\end{aligned}
$$

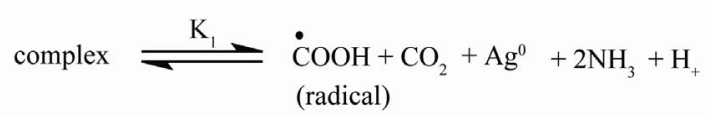

(Radical follows the same reaction as shown in Scheme 1)

Scheme 2. Oxidation of oxalic acid by Ag-ammonia complex.

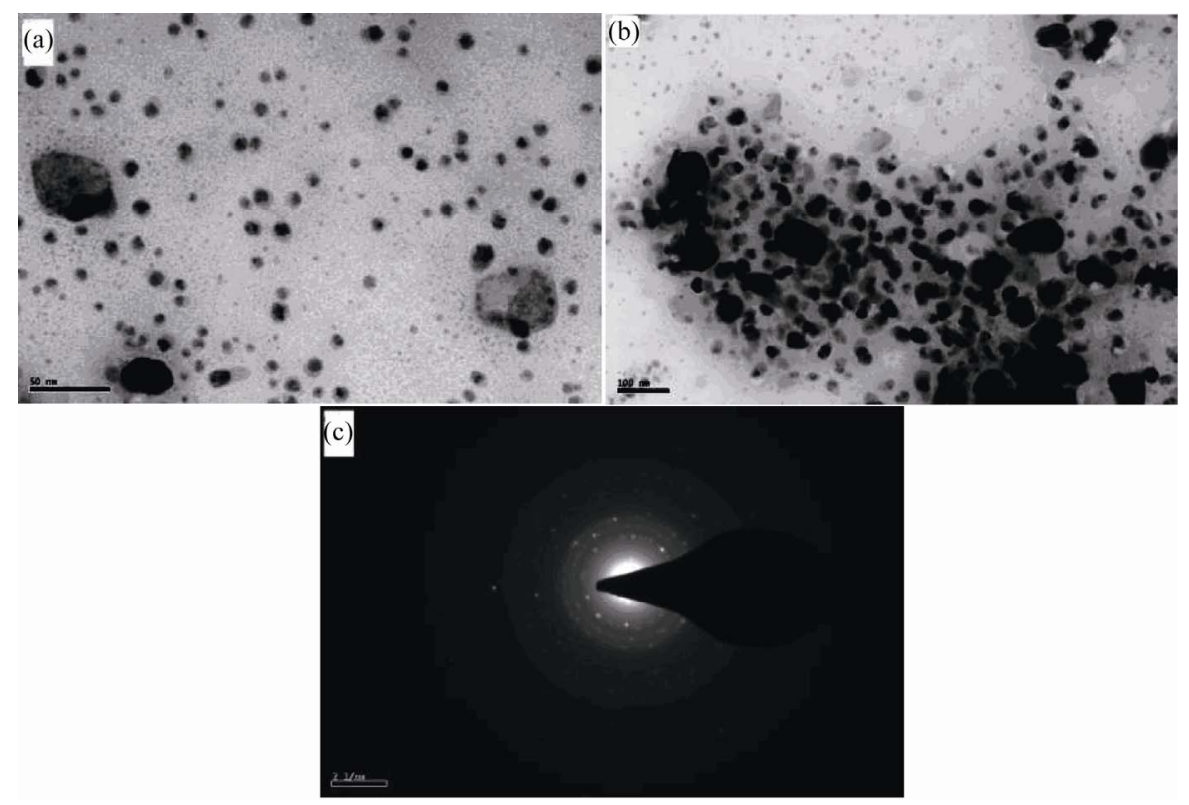

Figure 5. TEM images of Ag-NP. Reaction conditions: $[0 x a$ alic acid $]=4.0 \times 10^{-4} \mathrm{~mol} \cdot \mathrm{dm}^{-3},\left[\mathrm{Ag}^{+}\right]=20.0 \times 10^{-4} \mathrm{~mol}^{\circ} \cdot \mathrm{dm}^{-3}$ and CTAB $=10.0 \times 10^{-4} \mathrm{~mol} \cdot \mathrm{dm}^{-3}$.
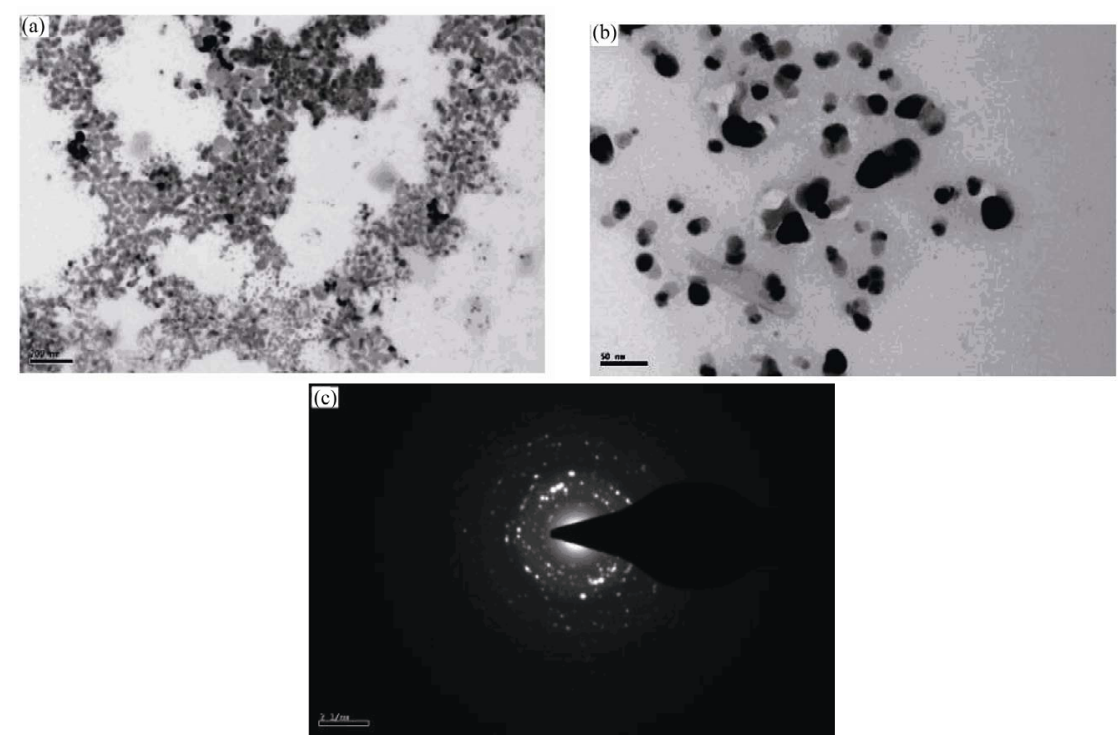

Figure 6. TEM images of Ag-NP. Reaction conditions: $\left[\right.$ oxalic acid] $=4.0 \times 10^{-4} \mathrm{~mol} \cdot \mathrm{dm}^{-3},\left[\mathrm{Ag}^{+}\right]=20.0 \times 10^{-4} \mathrm{~mol}^{-1} \mathrm{dm}^{-3}$ and CTAB $=10.0 \times 10^{-4} \mathrm{~mol} \cdot \mathrm{dm}^{-3}$ in presence of $\left[\right.$ ammonia] $=20.0 \times 10^{-4} \mathrm{~mol} \cdot \mathrm{dm}^{-3}$. 
red color prepared by the oxalic acid- $\mathrm{Ag}^{+}$reaction in absence and presence of ammonia). One can see well-dispersed spherical Ag-NP, with size ranging from 3.5 to $9 \mathrm{~nm}$ and a monodisperse size distribution can be easily evidenced from the TEM image of Figure 5(a). The sol is quite polydisperse. The monodispersity is manifested also in the 2D hexagonal colloidal assemblies observed in most of the micrographs we scanned [53]. As can be seen in Figure 6(a) and (b) (typical example), show that the particles are spherical, polydispersed, and small-sized of diameter $c a .16 \mathrm{~nm}$ in presence of ammonia. Interestingly, the CTAB stabilized Ag-NP were formed faster than in the CTAB + ammonia containing silver sols. TEM image of Figure 6(a) also reveal that these Ag-NP aggregate and/or deposited onto the surface of particles in an unsymmetric manner to form necklace-like structure. Such type of aggregation we did not observed without ammonia. Presence of ammonia, decreased the nucleation rate, because the ammonia present in the reaction mixture reduce the reduction potential of $\mathrm{Ag}^{+}$ions which inhibit the particle nucleation and growth (Table 1). As a result, the size of the particles is higher in presence of ammonia. Comparison of spectroscopic, kinetic and TEM data clearly indicates that the shape, the size distribution, nature of reaction-time curves, mechanism, aggregation, and polydispersity strongly depends on the presence of [ammonia]. The crystalline nature of the Ag-NP was revealed by the electron diffraction patterns. The typical selected-area diffraction pattern are shown in Figures 5(c) and 6(c) and it clearly exhibited diffraction rings with interplanar spacing The rings patterns are consistent with the plane families $\{110\},\{111\}$, $\{200\},\{220\},\{311\},\{331\}$ and $\{422\}$, of pure face-centred cubic silver structure in absence and presence of ammonia [54, 55].

\section{Conclusions}

The silver nanoparticles were prepared based on the reduction reaction of silver nitrate and oxalic acid using CTAB as a stabilizing agent. Additives and ammonia plays a major role in this method and their concentrations are an important parameter to determine the growth rate. TEM and selected area electron diffraction confirmed that formation of spherical, aggregated and face-centered-cubic Ag-NP, respectively. The AG-NP is stable in $\mathrm{NaNO}_{3}$ and $\mathrm{NaH}_{2} \mathrm{PO}_{4}$ solutions but the presence of $\mathrm{NaCl}$, $\mathrm{NaBr}$ and $\mathrm{Na}_{2} \mathrm{SO}_{4}$ causes their aggregation.

\section{REFERENCES}

[1] V. Iliev, D. Tomova, L. Bilyarska, A. Eliyas and L. Petrov, "Photocatalytic Properties of $\mathrm{TiO}_{2}$ Modified with Platinum and Silver Nanoparticles in the Degradation of Oxalic Acid in Aqueous Solution," Applied Catalysis B:
Environmental, Vol. 63, No. 3-4, 2006, pp. 266-271. doi:10.1016/j.apcatb.2005.10.014

[2] V. Iliev, D. Tomova, L. Bilyarska and G. Tyuliev, "Influence of the Size of Gold Nanoparticles Deposited on $\mathrm{TiO}_{2}$ upon the Photocatalytic Destruction of Oxalic Acid," Journal of Molecular Catalysis A: Chemical, Vol. 263, No. 1-2, 2007, pp. 32-38. doi:10.1016/j.molcata.2006.08.019

[3] V. Iliev, D. Tomova, S. Rakovsky, A. Eliyas and G. Li Puma, "Enhancement of Photocatalytic Oxidation of Oxalic Acid by Gold Modified $\mathrm{WO}_{3} / \mathrm{TiO}_{2}$ Photocatalysts under UV and Visible Light Irradiation," Journal of Molecular Catalysis A: Chemical, Vol. 327, No. 1-2, 2010, pp. 51-57. doi:10.1016/j.molcata.2010.05.012

[4] S. Song, J. Tu, L. Xu, X. Xu, Z. He, J. Qiu, J. Ni and J. Chen, "Preparation of a Titanium Dioxide Photocatalyst Codoped with Cerium and Iodine and Its Performance in the Degradation of Oxalic Acid," Chemosphere, Vol. 73, No. 9, 2008, pp. 1401-1406. doi:10.1016/j.chemosphere.2008.08.032

[5] S. Navaladian, B. Viswanathan, R. P. Viswanath and T. K. Varadarajan, "Thermal Decomposition as Route for Silver Nanoparticles," Nanoscale Research Letters, Vol. 2, No. 1, 2007, 44-48. doi:10.1007/s11671-006-9028-2

[6] S. Navaladian, B. Viswanathan, T. K. Varadarajan and R. P. Viswanath, "Microwave-Assisted Rapid Synthesis of Anisotropic Ag Nanoparticles by Solid State Transformation," Nanotechnology, Vol, 19, 2008, pp. 45603- 45609. doi:10.1088/0957-4484/19/04/045603

[7] M. Itoh, T. Kakuta, M. Nagaok, Y. Koyama, M. Sakamoto, S. Kawasaki, N. Umeda and M. Kurihara, "Direct Transformation into Silver Nanoparticles via Thermal Decomposition of Oxalate-Bridging Silver Oleylamine Complexes," Journal for Nanoscience and Nanotechnology, Vol. 9, No. 11, 2009, pp. 6655-6660. doi:10.1166/jnn.2009.1324

[8] V. K. Sharma, R. A. Yngard and Y. Lin, "Silver Nanoparticles: Green Synthesis and Their Antimicrobial Activities," Journal of Colloid and Interface Science, Vol. 145, No. 1-2, 2009, pp. 83-96. doi:10.1016/j.cis.2008.09.002

[9] F. Zaera, A. J. Gellman and G. A. Somorjai, "Surface Science Studies of Catalysis: Classification of Reactions," Accounts of Chemical Research, Vol. 19, No. 1, 1986, pp. 24-31. doi:10.1021/ar00121a004

[10] J. H. Fendler, "Atomic and Molecular Clusters in Membrane Mimetic Chemistry," Chemical Reviews, Vol. 87, No. 5, 1987, pp. 877-899. doi:10.1021/cr00081a002

[11] L. N. Lewis, "Chemical Catalysis by Colloids and Clusters," Chemical Reviews, Vol. 93, No. 8, 1993, pp. 26932730. doi: $10.1021 / \mathrm{cr} 00024 \mathrm{a} 006$

[12] T. Pal, T. K. Sau and N. R. Jana, "Reversible Formation and Dissolution of Silver Nanoparticles in Aqueous Surfactant Media," Langmuir, Vo. 13, No. 6, 1997, pp. 14811485. doi:10.1021/la960834o

[13] M. S. Bakshi, F. Possmayer and N. O. Petersen, "Role of Different Phospholipids in the Synthesis of Pearl-Neck- 
lace-Type Gold-Silver Bimetallic Nanoparticles as Bioconjugate Materials," Journal of Physical Chemistry C, Vol. 111, No. 38, 2007, pp. 14113-14124. doi:10.1021/jp072862t

[14] P. Khullar, A. Mahal, V. Singh, T. S. Banipal, G. Kaur and M. S. Bakshi, "How PEO-PPO-PEO Triblock Polymer Micelles Control the Synthesis of Gold Nanoparticles: Temperature and Hydrophobic Effects," Langmuir, Vol, 26, No. 13, 2010, pp. 11363-11371. doi:10.1021/la100734p

[15] P. Ball, "When Size Does Matter," Nature, Vol. 349, No. 6305, 1991, p. 101. doi:10.1038/349101a0

[16] X. Tian, W. Wang and G. Cao, "A Facile Aqueous-Phase Route for the Synthesis of Silver Nanoplates," Materials Letters, Vol. 61, No. 1, 2007, pp. 130-133. doi:10.1016/j.matlet.2006.04.021

[17] M. P. Pileni, "Reverse Micelles as Microreactors," Journal of Physical Chemistry, Vol. 97, No. 27, 1993, pp. 6961-6973. doi:10.1021/j100129a008

[18] D. E. Tembe and M. M. Sharma, "Factors Controlling the Stability of Colloid-Stabilized Emulsions: I. An Experimental Investigation," Journal of Colloid and Interface Science, Vol. 157, No. 1, 1993, pp. 244-253. doi:10.1006/jcis.1993.1182

[19] X. Zhai and S. Efrima, "Chemical and Physical Aspects of Macroemulsions Stabilized by Interfacial Colloids," Journal of Physical Chemistry, Vol. 100, No. 26, 1996, pp. 11019-11028. doi:10.1021/jp953171c

[20] S. De, A. Pal, N. R. Jana and T. Pal, "Anion Effect in Linear Silver Nanoparticle Aggregation as Evidenced by Efficient Fluorescence Quenching and SERS Enhancement," Journal of Photochemistry and Photobiology A: Chemistry, Vol. 131, No. 1, 2000, pp. 111-123. doi:10.1016/S1010-6030(99)00231-2

[21] P. Mulvaney and A. Henglein, "Long-Lived Nonmetallic Silver Clusters in Aqueous Solution: A Pulse Radiolysis Study of Their Formation," Journal of Physical Chemistry, Vol. 94, No. 10, 1990, pp. 4182-4188. doi: $10.1021 / \mathrm{j} 100373 \mathrm{a} 056$

[22] T. Linnert, P. Mulvaney and A. Henglein, "Surface Chemistry of Colloidal Silver: Surface Plasmon Damping by Chemisorbed Iodide, Hydrosulfide (SH-), and Phenylthiolate," Journal of Physical Chemistry, Vol. 97, No. 3, 1993, pp. 679-682. doi:10.1021/j100105a024

[23] A. Henglein, "Physicochemical Properties of Small Metal Particles in Solution: "Microelectrode" Reactions, Chemisorption, Composite Metal Particles, and the Atom-toMetal Transition," Journal of Physical Chemistry, Vol. 97, No. 21, 1993, pp. 5457-5471. doi:10.1021/j100123a004

[24] F. Strelow and A. Henglein, "Time Resolved Chemisorption of I- and SH- on Colloidal Silver Particles (A Stopped Flow Study)," Journal of Physical Chemistry, Vol. 99, No. 31, 1995, pp. 11834-11838. doi:10.1021/j100031a008

[25] A. Hanglein, "Colloidal Silver Nanoparticles: Photochemical Preparation and Interaction with $\mathrm{O}_{2}, \mathrm{CCl}_{4}$, and Some Metal Ions," Chemistry of Materials, Vol. 10, No.

\section{1, 1998, pp. 444-450. doi:10.1021/cm970613j}

[26] E. Janata, A. Henglein and B. G. Ershov, "First Clusters of $\mathrm{Ag}^{+}$Ion Reduction in Aqueous Solution," Journal of Physical Chemistry, Vol. 98, No. 42, 1994, pp. 1088810890. doi:10.1021/j100093a033

[27] D. Yu and V. W. W. Yam, "Hydrothermal-Induced Assembly of Colloidal Silver Spheres into Various Nanoparticles on the Basis of HTAB-Modified Silver Mirror Reaction," Journal of Physical Chemistry B, Vol. 109, No. 12, 2005, pp. 5497-5503. doi:10.1021/jp0448346

[28] A. T. Le, P. T. Huy, P. D. Tam, T. Q. Huy, P. D. Cam, A. A. Kudrinskiy and Y. A. Krutyakov, "Green Synthesis of Finely-Dispersed Highly Bactericidal Silver Nanoparticles via Modified Tollens Technique," Current Applied Physics, Vol. 10, No. 3, 2010, pp. 910-916. doi:10.1016/j.cap.2009.10.021

[29] A. G. Ingalls, "Amateur Telescope Making (Book one)," Scientific American Ind., New York, 1981, p. 101.

[30] S. Huang and A. W. H. Mau, "Selective Growth of Aligned Carbon Nanotubes on a Silver-Patterned Substrate by the Silver Mirror Reaction," Journal of Physical Chemistry B, Vol. 107, No. 15, 2003, pp. 3455-3458. doi: $10.1021 / \mathrm{jp} 034282 \mathrm{~b}$

[31] P. Mukherjee and K. J. Mysels, "Critical Micelle Concentrations of Aqueous Surfactants, NSRDS-NBS \# 36," Superintendent of Documents, Washington, DC, 1971.

[32] Z. Zhong, S. Patskovskyy, P. Bouvrette, J. H. T. Luong and A. Gedanken, "The Surface Chemistry of Au Colloids and Their Interactions with Functional Amino Acids," Journal of Physical Chemistry B, Vol. 108, No. 13, 2004, pp. 4046-4052. doi:10.1021/jp037056a

[33] Z. Khan, P. Kumar, Kabir-ud-Din, "Kinetics and Mechanism of the Reduction of Colloidal Manganese Dioxide by D-Fructose," Colloids and Surfaces A: Physicochemical and Engineering Aspects, Vol. 248, No. 1-3, 2004, pp. 25-31. doi:10.1016/j.colsurfa.2004.08.020

[34] R. Bacaloglu, C. A. Bunton and F. Ortega, "Micellar Enhancements of Rates of SN2 Reactions of Halide Ions: The Effect of Head Group Size," Journal of Physical Chemistry, Vol. 93, No. 4, 1989, pp. 1497-1502. doi:10.1021/j100341a061

[35] C. Tondre and M. Hebrant, "Micellar and Microemulsion Systems to Perform Heterogeneous Reactions, Biphasic Extraction and Solute Transport," Journal of Molecular Liquids, Vol. 72, No. 1-3, 1997, pp. 279-294. doi:10.1016/S0167-7322(97)00042-1

[36] A. Henglein, "Colloidal Silver Nanoparticles: Photochemical Preparation and Interaction with $\mathrm{O}_{2}, \mathrm{CCl}_{4}$, and Some Metal Ions," Chemistry of Materials, Vol. 10, No. 1, 1998, pp. 444-450. doi:10.1021/cm970613j

[37] Z. Y. Huang, G. Mills and B. "Hajek, Spontaneous Formation of Silver Particles in Basic 2-Propanol," Journal of Physical Chemistry, Vol. 97, No. 44, 1993, pp. 1154211550. doi: $10.1021 / \mathrm{j} 100146 \mathrm{a} 031$

[38] A. Rafey, K. B. L. Shrivastav, S. A. Iqbal and Z. Khan, "Growth of Ag-nanoparticles Using Aspartic Acid in Aqueous Solutions," Journal of Colloid and Interface 
Science, Vol. 534, No. 3, 2011, pp. 190- 195. doi:10.1016/j.jcis.2010.10.046

[39] S. Tascioglu, "Micellar Solutions as Reaction Media," Tetrahedron, Vol. 52, No. 34, 1996, pp. 11113-11152. doi:10.1016/0040-4020(96)00669-2

[40] Kabir-ud-Din, J. K. J. Salem, S. Kumar and Z. khan, "The Micelle-Induced Interaction between Ninhydrin and Tryptophan," Journal of Colloid and Interface Science, Vol. 215, No. 1, 1999, pp. 9-15. doi:10.1006/jcis.1999.6211

[41] H. A. Al-Lohedan, C. A. Bunton and L. S. Romsted, "Micellar Effects upon the Reaction of Betaine Esters with Hydroxide Ion," Journal of Physical Chemistry, Vol. 85, No. 14, 1981, pp. 2123-2129. doi:10.1021/j150614a034

[42] C. A. Bunton and J. R. Moffatt, "Micellar Effects upon Substitutions by Nucleophilic Anions," Journal of Physical Chemistry, Vol. 92, No. 10, 1988, pp. 2896-2902. doi:10.1021/j100321a038

[43] D. Longa, G. Wua and S. Chen, "Preparation of Oligochitosan Stabilized Silver Nanoparticles by Gamma Irradiation," Radiation Physics and Chemistry, Vol. 76, No. 7, 2007, pp. 1126-1131. doi:10.1016/j.radphyschem.2006.11.001

[44] R. A. Alvarez-Puebla, E. Arceo, P. J .G. Goulet, J. J. Garrido and R. F. Aroca, "Role of Nanoparticle Surface Charge in Surface-Enhanced Raman Scattering," Journal of Physical Chemistry B, Vol. 109, No. 9, 2005, pp. 3787-3792. doi:10.1021/jp045015o

[45] H. A. Al-Lohedan, C. A. Bunton and J. R. Moffatt, "Quantitative Treatment of Micellar Effects upon the Nucleophilicity of Halide Ions," Journal of Physical Chemistry, Vol. 87, No. 2, 1983, pp. 332-335. doi:10.1021/j100225a033

[46] H. A. Al-Lohedan, "Nucleophilicity of Halide Ions in the Micellar Pseudophase," Tetrahedron, Vol. 45, No. 6, 1987, pp. 1747-1754. doi:10.1016/S0040-4020(01)80038-7

[47] Y. Sato, J. J. Wang, D. N. Batchelder and D. A. Smith, "Simple Chemical Method for Forming Silver Surfaces with Controlled Grain Sizes for Surface Plasmon Experiments," Langmuir, Vol. 19, No. 17, 2003, pp. 68576861. doi: $10.1021 / \mathrm{la} 0301240$
[48] L. Kvitek, A. Panacek, J. Soukupova, M. Kolar, R. Vecerova, R. Prucek, M. Holecova and R. Zboril, "Effect of Surfactants and Polymers on Stability and Antibacterial Activity of Silver Nanoparticles (NPs)," Journal of Physical Chemistry C, Vol. 112, No. 15, 2008, pp. 5825-5834. doi:10.1021/jp711616v

[49] J. Soukupova, L. Kvitek, A. Panacek, T. Nevecna and R. Zboril, "Comprehensive study on Surfactant Role on Silver Nanoparticles (NPs) Prepared via Modified Tollens Process," Materials Chemistry and Physics, Vol. 111, No. 1, 2008, pp. 77-81. doi:10.1016/j.matchemphys.2008.03.018

[50] D. V. Goia and E. Matijevic, "Preparation of Monodispersed Metal Partials," New Journal of Chemistry, Vol. 22, No. 11, 1998, pp. 1203-1215. doi:10.1039/a709236i

[51] A. Henglein, "Small-Particle Research: Physicochemical Properties of Extremely Small Colloidal Metal and Semiconductor Particles," Chemical Reviews, Vol. 89, No. 8, 1989, pp. 1861-1873. doi:10.1021/cr00098a010

[52] M. Nishizawa, Y. Sasaki and K. Saito, "Kinetics and Mechanisms of the Outer-Sphere Oxidation of CisAquaoxovanadium(IV) Complexes Containing Quadrindentate Amino Polycarboxylates. Interpretation of the Difference in Activation Parameters with the Charge Type of Reactants," Inorganic Chemistry, Vol. 24, No. 5, 1985, pp. 767-772. doi:10.1021/ic00199a028

[53] W. Wang, X. Chen and S. Efrima, "Silver Nanoparticles Capped by Long-Chain Unsaturated Carboxylates," Journal of Physical Chemistry B, Vol. 103, No. 34, 1999, pp. 7238-7246. doi:10.1021/jp991101q

[54] M. G. Guzman, J. Dille and S. Godet, "Synthesis of Silver Nanoparticles by Chemical Reduction Method and Their Antibacterial Activity," World Academy of Science, Engineering and Technology, Vol. 43, 2008, pp. 357-364.

[55] A. Serra, E. Filippo, M. Re, M. Palmisano, M. VittoriAntisari, A. Buccolieri and D. Manno, "Non-functionalized Silver Nanoparticles for a Localized Surface Plasmon Resonance-Based Glucose Sensor," Nanotechnology, Vol. 20, No. 16, 2009, pp. 165501-165508. doi:10.1088/0957-4484/20/16/165501 